\title{
Coexpression analysis of CD133 and CD44 identifies Proneural and Mesenchymal subtypes of glioblastoma multiforme
}

\author{
Daniel V. Brown ${ }^{1}$, Paul M. Daniel ${ }^{1}$, Giovanna M. D'Abaco ${ }^{2,3}$, Andrew Gogos ${ }^{2}$, Wayne \\ $\mathbf{N g}^{2}$, Andrew P. Morokoff ${ }^{2}$ and Theo Mantamadiotis ${ }^{1}$ \\ ${ }^{1}$ Department of Pathology, University of Melbourne, Melbourne, Australia \\ ${ }^{2}$ Department of Surgery (RMH), University of Melbourne, Parkville, Victoria, Australia \\ ${ }^{3}$ Centre for Neural Engineering, University of Melbourne, Parkville, Victoria, Australia \\ Correspondence to: Theo Mantamadiotis, email: theom@unimelb.edu.au
}

Keywords: coexpression, cancer genome atlas, glioblastoma, molecular subtype, cancer stem cells

Received: December 06, $2014 \quad$ Accepted: January 12, $2015 \quad$ Published: January 31, 2015

This is an open-access article distributed under the terms of the Creative Commons Attribution License, which permits unrestricted use, distribution, and reproduction in any medium, provided the original author and source are credited.

\section{ABSTRACT}

Accumulating evidence suggests that the stem cell markers CD133 and CD44 indicate molecular subtype in Glioblastoma Multiforme (GBM). Gene coexpression analysis of The Cancer Genome Atlas GBM dataset was undertaken to compare markers of the Glioblastoma Stem-Progenitor Cell (GSPC) phenotype. Pearson correlation identified genes coexpressed with stem cell markers, which were then used to build a gene signature that classifies patients based on a CD133 coexpression module signature (CD133-M) or CD44-M subtype. CD133-M tumors were enriched for the Proneural (PN) GBM subtype compared to Mesenchymal (MES) subtype for CD44-M tumors. Gene set enrichment identified DNA replication/cell cycle genes in the CD133-M and invasion/migration in CD44-M, while functional experiments showed enhanced cellular growth in CD133 expressing cells and enhanced invasion in cells expressing CD44. As with the 4 major molecular subtypes of GBM, there was no long-term survival difference between CD44-M and CD133-M patients, although CD44-M patients responded better to temozolomide while CD133-M patients benefited from radiotherapy. The use of a targeted coexpression approach to predict functional properties of surface marker expressing cells is novel, and in the context of GBM, supports accumulating evidence that CD133 and CD44 protein marker expression correlates with molecular subtype.

\section{INTRODUCTION}

Glioblastoma Multiforme (GBM) is an aggressive, heterogeneous tumor of the central nervous system. The diverse features of the tumor have made management of GBM difficult [1]. GBM has a 5 year survival of less than $5 \%$, rendering it one of the most lethal types of tumors [2]. Molecular profiling of patient specimens has revealed that GBM consists of several distinct subtypes with characteristic mutational, transcriptional and epigenetic profiles. Subtype classification is based on the similarity of the gene expression profiles with the major stages of neural development, Proneural (PN), Neural, Classical and Mesenchymal (MES) [3-5].

GBM is typically treated by a combination of surgical resection, radiotherapy and chemotherapy with temozolomide. Poor patient survival in GBM is due to the recurrence of the tumor despite therapy $[6,7]$. It has been suggested that the inevitable recurrence is driven by a subpopulation of GBM cells with stem cell properties, glioma stem-progenitor cells (GSPCs) or glioma initiating cells (GICs) [8].

Understanding the underlying biology of GSPCs relies on the large body of knowledge derived from fundamental stem cell research. Advances in stem cell research has heavily relied on the ability to enrich rare subpopulations of cells for downstream characterization using fluorescence activated cell sorting (FACS) [9, 10]. FACS relies on a robust extracellular protein marker or combination of markers based on prospective characterization of the phenotypic properties of the cells defined by those markers. Therefore the choice of FACS 
Table 1: GSPC markers selected for analysis.

\begin{tabular}{|c|c|c|}
\hline Marker & Function & Reference \\
\hline CD133 (PROM1) & Unknown biological function & {$[8]$} \\
\hline CD44 & Hyaluronan binding & {$[19]$} \\
\hline CD15 (FUT4) & Transfer fucose to polysaccharides & {$[20]$} \\
\hline Integrin- $\alpha 6$ & Subunit for laminin receptor & {$[22]$} \\
\hline L1CAM & Cell-cell adhesion in neural lineage & {$[21]$} \\
\hline ALDH1A3 & Detoxification of aldehydes generated by metabolism & {$[37]$} \\
\hline
\end{tabular}

marker is crucial in the experimental design of cancer stem cell studies. GSPCs were initially characterized based on the expression of the stem cell marker CD133 (expressed by the PROM1 gene) [8, 11]. CD133+ cells were demonstrated to exhibit robust cancer stem cell/ tumorigenic potential compared to CD133- cells when as few as $100 \mathrm{CD} 133+$ cells are transplanted into immunodeficient mice [12].

Although a number of studies have supported the prognostic value of CD133 in GBM [13-15] there are reports that $\mathrm{CD} 133$ expression is not restricted to GSPCs, and that CD133- cells also exhibit stem cell characteristics [16-18]. A variety of other stem cell markers have also been investigated in GBM including the adhesion molecules CD44, Integrin- $\alpha 6, \mathrm{CD} 15$ (also known as SSEA-1 expressed by the FUT4 gene) and the expression and activity of ALDH1A3 [19-22].

Gene expression profiling experiments show that GSPCs exhibit a similar molecular classification to the parental bulk GBM tumor, with 2 clusters of cells representing the PN and MES subtype [23, 24]. Phenotypically, PN cells exhibit non-adherent sphere forming growth in vitro and circumscribed, non-invasive growth in vivo. In contrast, MES cells grow semiadherently in vitro and show invasive growth in vivo $[24,25]$. It has recently been shown that the PN subtype predominantly expresses CD133 or CD15 at the cell surface, whereas the MES subtype expresses CD44 [25, 26].

To determine the precise context of the relationship between the cancer stem cell phenotype, molecular subtype and the expression of extracellular stem cell markers we have used publicly available gene expression data of GBM and GSPC samples to perform coexpression analysis. The utility of coexpression analysis has been previously demonstrated in various cancers, including GBM, through the identification of novel genetic modules, allowing for more precise molecular subclassification of tumor subtypes and the possibility that this information could be used in precision medicine based therapeutic strategies [27-29].

Based on the hypothesis that gene sets/modules coexpressed with specific cell surface markers contribute to the phenotype of the overall tumor, we studied gene signatures derived from the coexpression modules of several stem cell markers. We demonstrate that, in the context of GBM tumor tissue, expression of coexpression modules associated with CD133, CD44 and CD15 mRNA are markers of GBM molecular subtype independent of cancer stem cell molecular signatures.

\section{RESULTS}

\section{Coexpression analysis of Glioblastoma cancer stem cell markers}

To investigate the biological and clinical significance of selected putative cancer stem cell markers (Table 1) in GBM, a coexpression analysis was undertaken using The Cancer Genome Atlas (TCGA) Agilent microarray dataset. The Agilent dataset (483 patients) demonstrated more normally distributed gene expression profiles compared to the Affymetrix U133a dataset (539 patients) (Figure S1A and B). The top 5\% of significant positively correlated genes (332-674 genes in length) with each cell surface marker mRNA was used to build a coexpression module (Table S1).

Positively correlated genes were selected for the signatures as they are expressed in the population with the stem cell marker and therefore are able to be detected, unlike negatively correlated genes.

The CD133 module signature (CD133-M) was negatively correlated with CD44, whereas the CD44 and CD15 module signatures (CD44-M and CD15-M) were highly correlated with each other (Figure S1C and D). It is interesting to note that there are no genes that are positively correlated with both CD133-M and CD44-M.

The greater overlap of CD44-M and CD15-M with the MES subtype was likely due to the greater magnitude of the Pearson correlation coefficients for genes coexpressed with CD44 mRNA compared to CD133 mRNA (Figure S1E), due to higher absolute expression of CD44 mRNA in the GBM tumors (Figure S2A). As recent reports suggest a subset of cancer stem cell markers enrich for characteristic GBM molecular subtypes [25, 26], coexpression modules were compared to the assigned molecular subtype for each patient. The TCGA RNAseq GBM dataset was utilized as an independent technical platform from the Agilent array dataset, to investigate association with molecular subtype.

The coexpression modules derived from CD133, 
CD44 and CD15 mRNA expression showed a striking pattern of overlap with the two most distinct molecular subtypes, PN and MES (Figure 1A). CD133-M was highly enriched in the PN molecular subtype ( $p$-value 4.2 e-08, Wilcoxon rank sum test). The number of genes shared between CD133-M and PN signatures was also significant at 31 genes (p-value 8.6e-16, hypergeometric test) (Table S2). Conversely CD44-M was enriched in the MES subtype (p-value 9.7e-14) and the number of genes that overlapped was greater at 106 genes (p-value $1.3 \mathrm{e}$ 106), (Figure 1A). The number of genes shared between CD15 and MES signatures was 97, (p-value 5.93e-91), slightly smaller than for CD44-MES (Table S2). Given the redundancy (overlap) for CD44-M and CD15-M in marking the MES molecular subtype in our analyses, we focused primarily on a CD133/ CD44 classification based on the coexpression modules derived from these markers.

Although the CD133-M/ CD44-M classification separates PN from MES molecular subtypes the distribution of CD133-M/ CD44-M was not significant in Classical tumors ( $\mathrm{p}$-value 0.53 , binomial test) or Neural tumors (p-value 0.85, Figure 1B). The enrichment of CD133-M, CD44-M and CD15-M was reproduced in the independent Rembrandt dataset (Figure 1C) and the original Agilent TCGA dataset used in the coexpression analysis (Figure 1D).

Other markers tested showed a more scattered overlap with molecular subtype. Of note, the ALDH1A3

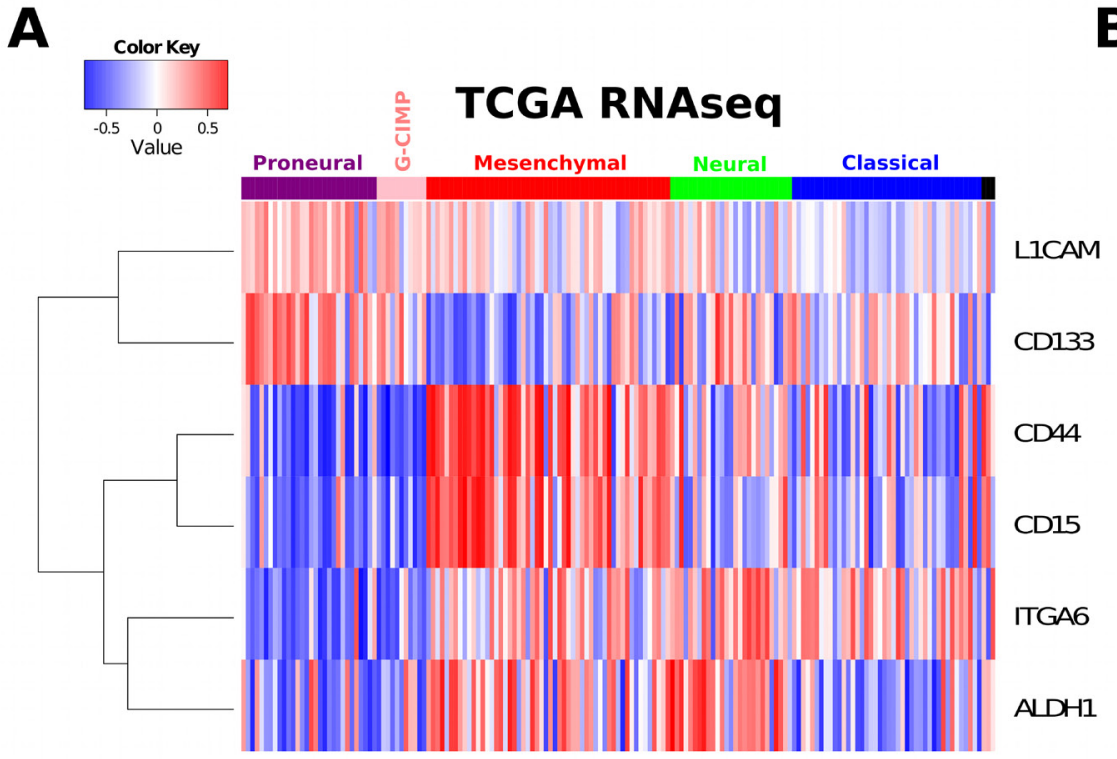

B

\section{TCGA patients}

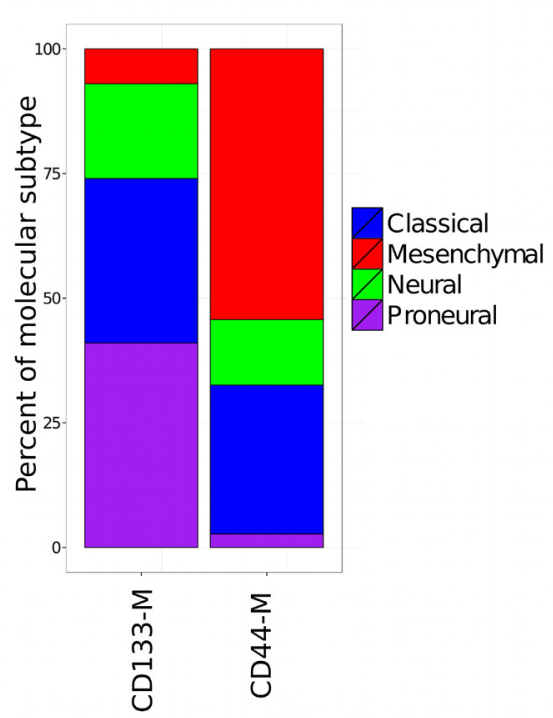

C

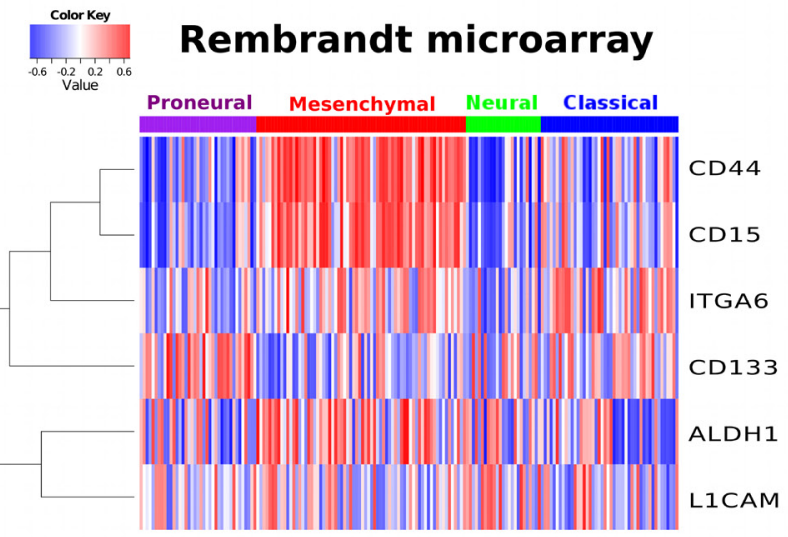

D

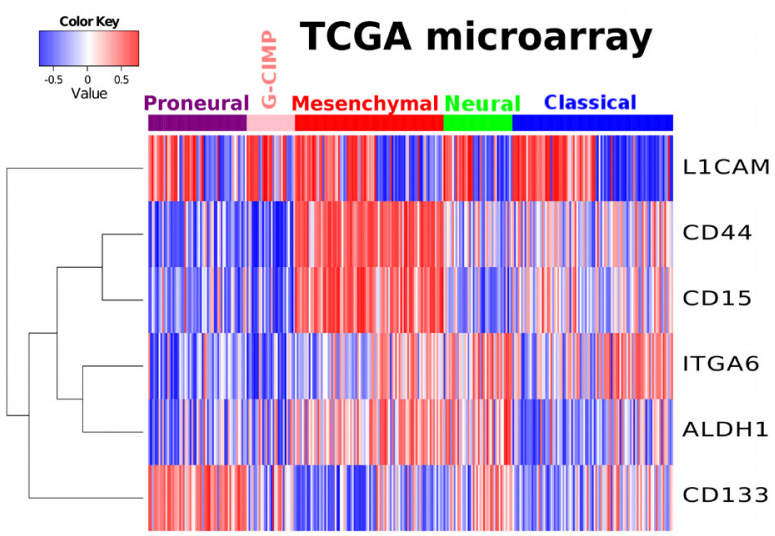

Figure 1: Cancer stem cell marker coexpression modules are associated with molecular subtype. (A) The coexpression module signatures of a range of stem cell markers was used to assign a patient specific similarity score. This score was then related to the assigned molecular subtype (top horizontal bar). (B) Enrichment of PN subtype in CD133-M and enrichment of CD44-M in MES. All patients in the 2013 data freeze were assigned to either a CD133 or CD44 coexpression module subtype (CD133-M or CD44-M) and the percentage of each molecular subtype within each coexpression subtype calculated. Coexpression module signature analysis of the Rembrandt (C) and (D) and the TCGA Agilent microarray dataset. 
module showed an association with the MES subtype as previously reported ( $\mathrm{p}$-value $1.5 \mathrm{e}-4$ ) [25].

The Integrin- $\alpha 6$ module was lower in the PN subtype compared to other subtypes, while the L1CAM marker was inconsistent in the Rembrandt dataset compared to the TCGA (Figure 1C). No marker tested could discriminate the G-CIMP subgroup of PN GBMs from the non G-CIMP PN subtype.

Coexpression analysis was also performed with the addition of intra-cellular markers related to neural differentiation (Figure S2C). The neural marker TUBB3 (also known as $\beta 3$-tubulin) and oligodendrocyte marker OLIG2 were associated with the PN subtype, as previously reported $[25,26]$. Conversely the astrocyte marker GFAP and mesenchymal marker YKL40 were associated with the MES subtype.

There were 3 broad clusters of coexpression modules that were associated with the GBM samples. One cluster was indicative of the MES subtype, another of
PN while a third contained markers of neural immaturity including nestin, Pax6 and ID1. Our data suggests that coexpression module signatures identify GBM molecular subtype better than either raw mRNA expression (Figure $\mathrm{S} 2 \mathrm{~A}$ ) or $\mathrm{z}$ score normalized mRNA expression in the TCGA (Figure S2B).

\section{The coexpression module subtypes of GBM are reflected in glioma stem-progenitor cell cultures}

We next investigated if glioma stem-progenitor cells (GSPCs) grown in vitro, reflected the coexpression modules identified using whole tumor derived gene expression measurements. Analysis of publicly available datasets confirms the mutual exclusivity of CD133-M and CD44-M (Figure 2A and B). For the gene expression study conducted by Bhat et al., (2013) the PN subtype assigned by the authors overlapped with CD133-M and the assigned
A

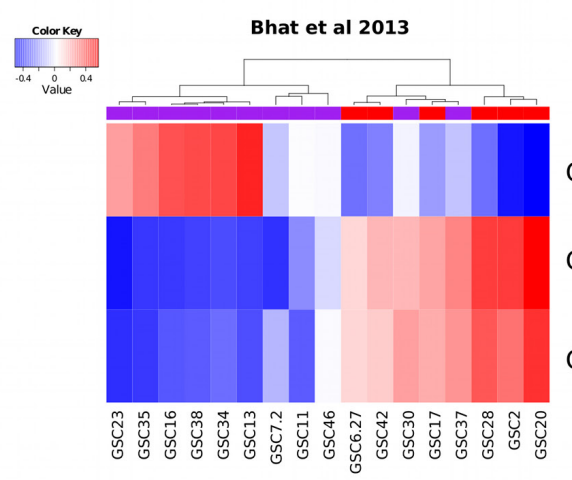

C

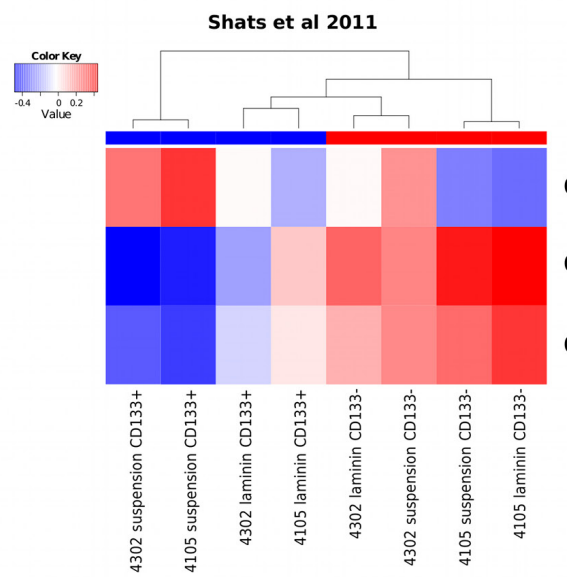

B

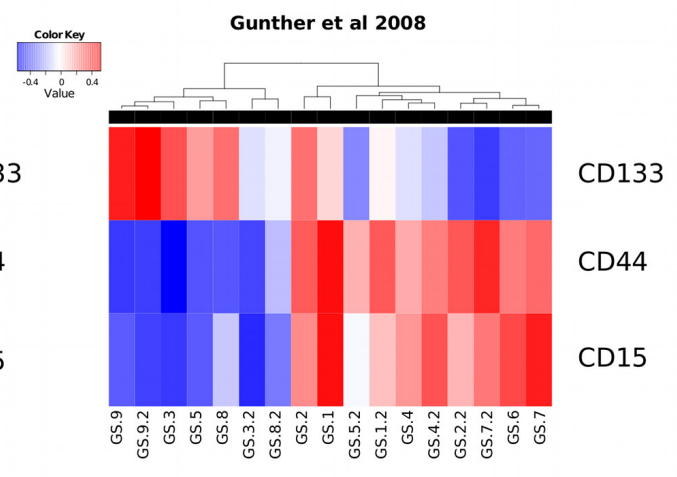

D

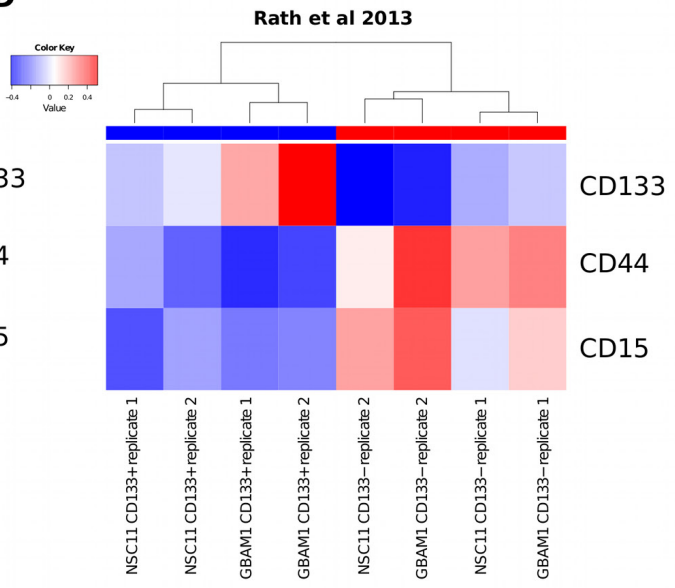

Figure 2: The coexpression modules identified in GBM tumors are reflected in GSPCs. (A) Coexpression module analysis of Bhat el al 2013 gene expression data. Hierarchical clustering of GSPC cultures by CD133-M and CD44-M partitions samples into 2 groups, largely overlapping with the assignment of PN (purple horizontal bar) and MES (red horizontal bar). (B) Coexpression module analysis of Gunther et al 2008 reveals 2 groups by clustering that largely overlap with the suspension or semi-adherent growth pattern described in the study. (C) Coexpression module analysis of Shats et al shows that CD133+ (blue) sorted cells are assigned to the CD133 coexpression signature and CD133- cells (red) are assigned to the CD44 coexpression signature. (D) Coexpression module analysis of Rath et al shows both normal neural and GBM cells that are CD133+ (blue) are enriched for CD133-M and CD133- cells are enriched for CD44-M (red). 
Table 2: Summary of functional categories enriched in genes coexpressed with GSPC markers.

\begin{tabular}{|c|c|c|}
\hline CD133 & CD44 & CD15 \\
\hline Fanconi pathway & Integrin1 pathway & Integrin1 pathway \\
\hline G2/ M checkpoints & Cytokine receptor pathway & Extracellular matrix organization \\
\hline Cell cycle & NOD-like receptor pathway & Integrin3 pathway \\
\hline Meiosis & Complement and coagulation cascades & Focal adhesion \\
\hline Chromosome maintenance & Interferon gamma signaling & ECM receptor interaction \\
\hline DNA replication & Integrin3 pathway & Leukocyte transendothelial migration \\
\hline Double strand break repair & ECM receptor interaction & TRAIL pathway \\
\hline Packaging of telomere ends & NFkB pathway & P53 downstream pathway \\
\hline
\end{tabular}

MES signature overlapped with CD44-M (Figure 2A) [26]. Likewise for the Gunther et al. (2008) dataset the coexpression modules overlapped with the growth pattern of the GSPCs described in the study, suspension for PN cells and semi-adherent for MES cells with the exception of 1 sample [30].

To investigate if CD133-M is enriched in CD133 protein expressing cells we reanalyzed the Shats et al. (2011) dataset which was based on gene expression profiling of CD133 sorted cells [31] (Figure 2C). As expected, CD133+ cells grown in suspension culture conditions were strongly positive for CD133-M. However, $\mathrm{CD} 133+$ cells grown on the adherent substrate laminin were more strongly associated with CD44-M, suggesting a shift towards a more MES-like subtype in adherent culture conditions. This is consistent with the role of CD44 in the binding of extracellular matrix molecules such as laminin [32]. Overall, CD133 - cells were associated with CD44-M, consistent with the pattern observed in a second dataset that included both normal neural stem cells and GSPCs (Figure 2D) [33].

\section{Coexpression analysis identifies pathways involved in tumorigenesis}

We next investigated pathways associated with the identified coexpressed genes by gene set enrichment analysis (GSEA). The Pearson correlation coefficient of all genes on the Agilent platform with CD133, CD44 and CD15 mRNA were used as input to GSEA [34]. Pathways highly correlated with CD133 mRNA expression included those involved in DNA repair, cell cycle and DNA replication (Figure $3 \mathrm{~A} \&$ Table 2). This suggests that tumors with high CD133 expression are more proliferative than tumors with low CD133 expression. This is more consistent with a progenitor or transit-amplifying cell, and not a quiescent stem cell. In contrast, GSEA of the intracellular stem cell marker Pax6 revealed an association with the Notch pathway, while expression of the neural stem/ progenitor marker nestin, was associated with an active Hedgehog pathway (Figure S3). Notch signaling has a role in the maintenance of stem cell identity [35] while the hedgehog pathway is involved in the regulation and identity of adult neural stem cells [36].

The validity of the analytical approach is strengthened as the top pathways enriched for each marker often reflected the known biological role of the protein
A

\section{CD133 coexpression signature}

Fanconi pathway

NES $=2.68$

FDR $<2 \times 10^{-5}$

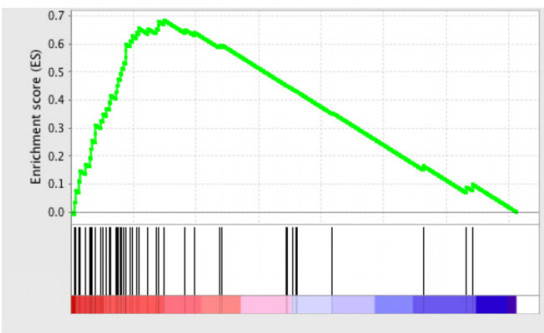

B

CD44 coexpression signature

Integrin 1 pathway

$\mathrm{NES}=2.93$

FDR $<2 \times 10^{-5}$

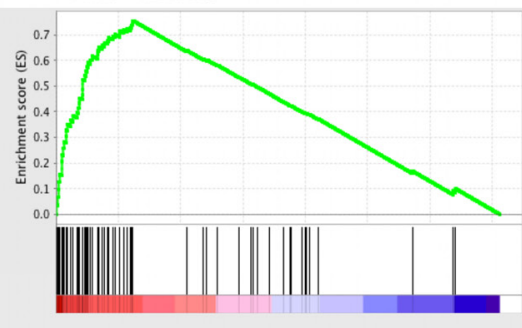

C

CD15 coexpression signature

Integrin 1 pathway

$\mathrm{NES}=2.76$

FDR $<2 \times 10^{-5}$

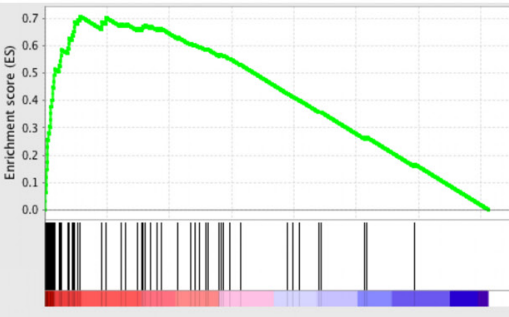

Figure 3: Enrichment of proliferative pathways for CD133-M and enrichment of invasive pathways for CD44-M and CD15-M. The Pearson correlation score of all genes with CD133, CD44 and CD15 mRNA was used as input to pre-ranked GSEA. (A) Enrichment of proliferative pathways in CD133 correlated genes. (B) and (C) Enrichment of invasive pathways for CD44 and CD15 correlated genes. 
Table 3: Hazard ratios for CD133-M and CD44-M GBM subtypes by treatment

\begin{tabular}{|c|c|c|c|}
\hline Subtype & Treatment & Hazard ratio (95\% CI) & p-value \\
\hline CD133-M & Temozolomide & $0.722(0.474$ to 1.097$)$ & 0.127 \\
\hline CD133-M & Radiation & $0.287(0.173$ to 0.477$)$ & $1.36 \mathrm{e}-6$ \\
\hline CD44-M & Temozolomide & $0.615(0.416$ to 0.908$)$ & 0.0145 \\
\hline CD44-M & Radiation & $0.512(0.298$ to 0.880$)$ & 0.154 \\
\hline
\end{tabular}

in question. ALDH1A3 is involved in the oxidation of intracellular aldehydes including retinol, producing retinoic acid [37]. The pathways associated with CD44 and CD15 included those involved in invasion and migration (Figure 3B and C). These pathways are consistent with the previously described role of CD44 as a MES marker in multiple cancer types [38]. In other cases there was no clear relationship between the pathways enriched by coexpression analysis and the stem cell marker, as for L1CAM and Sox2 (Figure S3).

\section{Functional validation of predicted signatures enriched in CD44 and CD133 expressing GSPCs}

To verify the coexpression analysis experimentally, functional assays were performed to test the hypotheses generated by gene set enrichment. The cell surface protein expression of CD15, CD44 and CD133 was examined in a panel of GSPC lines ('MUxx'), derived from patient tumors using flow cytometry (FACS). Similar to the coexpression module signatures there was a bias towards the expression of either CD133 (MU35), or CD44 (MU39 and MU41) (Figure 4A). However the relationship between expression of CD15 with CD44 or CD133 was not clear. For GPSC line MU39 CD15 was coexpressed with CD133. However MU35 did not express CD15 and MU41 expressed CD15 throughout the population (Figure 4A). It is of note that MU39 is unique in that there are 2 distinct subpopulations that express CD44 and CD133 respectively.

FACS sorted cells were examined for a range of phenotypes predicted by GSEA. Interestingly CD44+/ CD133+ cells had a significantly increased growth and self-renewal capacity demonstrated by the ability to form gliomaspheres at low dilution, a property of more stemlike cells (p-value 0.030 , Tukey post-hoc test following ANOVA), (Figure 4B). Cells expressing CD44 had a greater invasive ability with CD44+/ CD133- GSPCs exhibiting a significantly increased invasion index compared to CD44-/ CD133 - cells (p-value 0.007, Tukey post-hoc test), (Figure 4C). CD44+/ CD133+ GSPCs were more sensitive to temozolomide, in contrast to cells that expressed CD44 or CD133 alone (p-value 0.041, Tukey post-hoc test), (Figure 4D).

As proliferation and invasion are the phenotypes predicted by GSEA for CD44-M and CD133-M, the functional examination of CD44 and CD133 expressing cells in vitro, (Figure 4) validates the targeted coexpression approach to computationally assess cell surface markers used for flow cytometry.

\section{Examining the relationship between coexpression module signature and genomic alterations}

To further investigate the molecular differences between CD133-M and CD44-M classified patients, exome sequencing data was used to compare the overall number of somatic mutations between the 2 groups. In contrast to previously published findings [39], there was no difference in the total number of mutations for the CD133-M subtype compared to the CD44-M subtype (Figure S5A).

Pairwise testing for mutated genes enriched in each subgroup revealed that the CD133-M subtype was strongly enriched for IDH1 mutation with an odds ratio (OR) of 10.9, (p-value 5.91e-05, Fisher's exact test), (Figure S5B). TP53 mutations were also enriched (OR 2.60, p-value 0.0127). The NF1 gene which is characteristic of the MES subtype, was slightly above the threshold for statistical significance in the CD44-M subtype (OR 2.94, p-value 0.059 ). There was no other significant difference in genes commonly mutated in GBM, including PTEN, PIK3CA, PDGFRA and EGFR.

As epigenome status is intimately linked to gene expression, the relationship between the coexpression module subtypes and promoter methylation was examined. The CD44-M subtype was significantly associated with the M1 subtype (p-value 0.021 , binomial test with FDR [False Discovery Rate] correction). This is consistent with the M1/ MES molecular subtype enrichment previously described [5]. The CD133-M subtype was significantly enriched in the G-CIMP and M6 subtypes, methylation subgroups that are hyper and hypo- methylated respectively (p-value 10e-4 for both G-CIMP and M6 ). There was also a subtle but significant enrichment of CD133-M subtype in M3 (p-value 0.041) and CD44-M subtype in M2 (p-value 0.049). However, there was no difference in the methylation status of the MGMT promoter between the two groups (Figure S5B).

It has previously been reported that CD133 mRNA expression is negatively associated with IDH1 mutation and the G-CIMP group of Proneural GBMs [40]. Our analyses confirm this observation (p-value 0.006 , t-test) (Figure S5C). However it is interesting that there was no significant difference in CD133-M between G-CIMP patients and non G-CIMP patients. This indicates that 
A

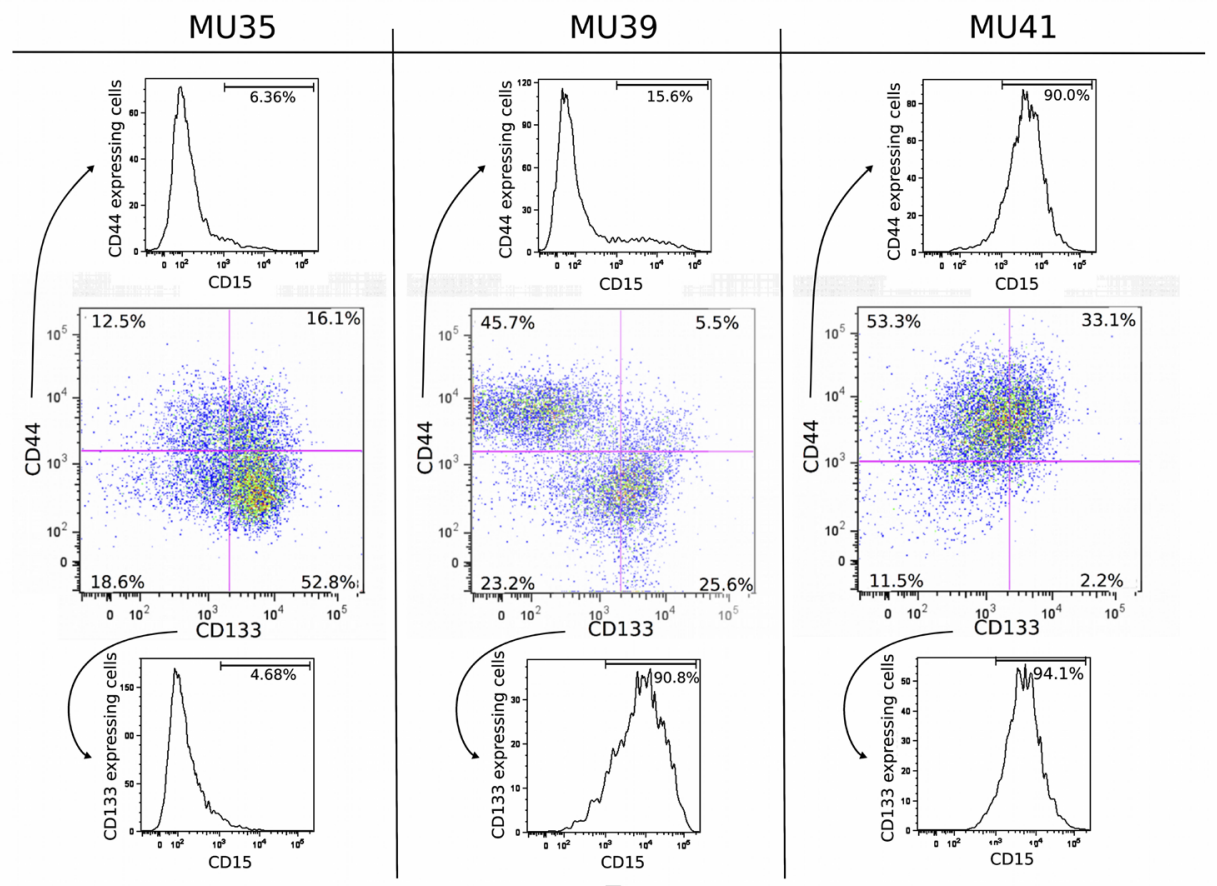

B

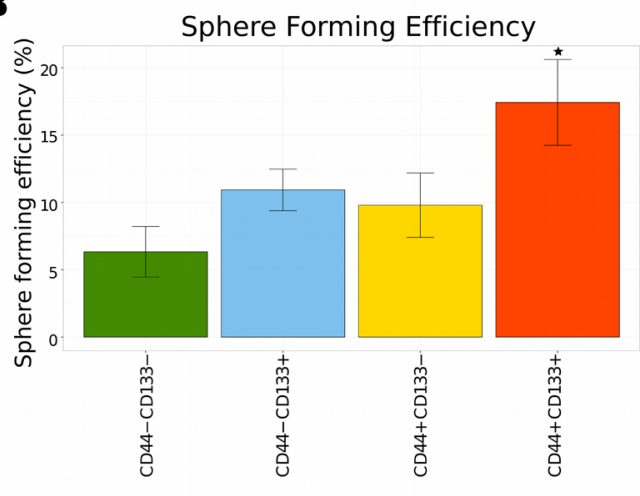

D

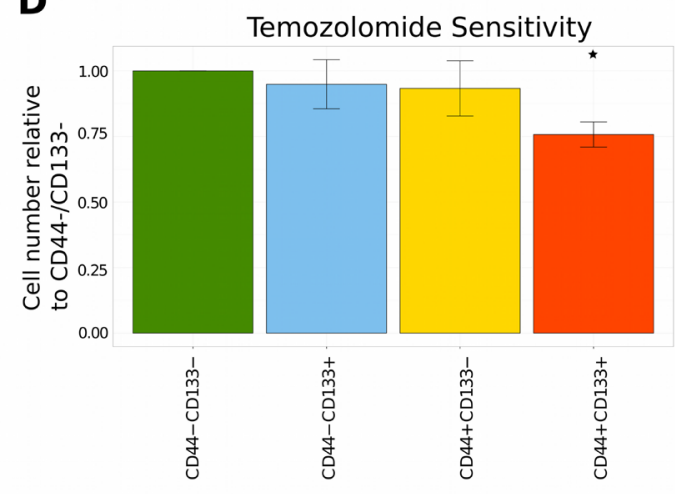

C

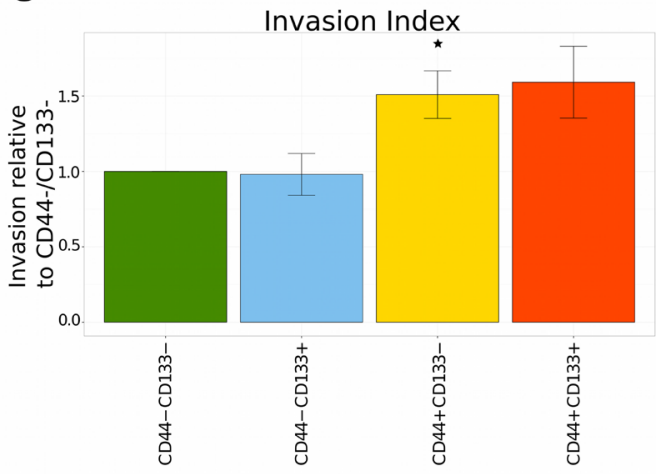


G-CIMP patient tumors share a gene expression profile similar to CD133-expressing tumors overall, despite a lack of CD133 mRNA expression.

Overall, the relationship between somatic mutations, methylation and coexpression subtype remains consistent with the notion that CD133-M is a marker of the PN molecular subtype and CD44-M identifies the MES subtype.

\section{CD44 and CD133 coexpression signatures predict temozolomide and radiation response}

Due to the observed overlap between CD133-M and the PN subtype and CD44-M and CD15-M with the MES subtype, we investigated the utility of a dichotomous CD133-M/ CD44-M classification to predict survival. As the number of genes coexpressed with both CD44 and CD15 was $30.4 \%$ (p-value 2.95e-144, hypergeometric test), we decided to focus on CD133 and CD44 coexpression module signatures in the survival analyses. Patients were classified as belonging to either CD133-M or CD44-M subtypes based on their gene set signature scores as computed by GSVA [41] (see methods). For the set of GBM patients assayed on the RNAseq platform, (TCGA) CD133-M subtype patients had a significant survival advantage compared to CD44-M subtype patients (p-value 0.016, log-rank test) (Figure 5A).

However there was no statistically significant difference in survival between CD133-M and CD44-M patients in either the Agilent cohort or the Rembrandt cohort of patients (Figure 5B) and (Figure S6). We could not identify any factors to explain the difference in survival between RNAseq and Agilent platforms aside from the timeframe within which the samples were collected (1989 - 2011 for Agilent microarray) and (1998 - 2011 for RNAseq). That there was no overall survival difference between CD44-M and CD133-M patients in Agilent and Rembrandt datasets is not unexpected as G-CIMP samples aside, there is no long-term difference in survival for the 4 major molecular subtypes of GBM [5].

There were however, differences in response to therapy for CD133-M and CD44-M classified patients in the Agilent cohort (Figure 5C - F). To investigate these factors further, a Cox proportional hazards model was constructed separately for CD133-M and CD44-M patients, incorporating age, G-CIMP status and exposure to radiotherapy and temozolomide (Table 3). CD133-M patients had significantly improved survival from radiotherapy treatment $(95 \% \mathrm{CI}$ hazard ratio $0.173-0.477)$ but no significant benefit from temozolomide (HR 0.474 - 1.097). In contrast, CD44-M patients received a greater survival benefit from temozolomide treatment (HR 0.416 to 0.908 ) and a greatly reduced benefit from radiotherapy (HR 0.298 to 0.880), compared to CD133-M patients.

\section{DISCUSSION}

This study is the first to demonstrate an association between cell surface markers and molecular subtype using gene expression profiles derived from large patient cohorts. Both TCGA and Rembrandt patient cohorts, as well as RNAseq and microarray technical platforms identified this association. Coexpression modules associated with putative cancer stem cell markers were identified and related to recognized molecular subtypes of GBM and clinical outcome. There was a significant overlap of CD133-M with the PN subtype and conversely CD44-M with the MES subtype. Association of these cell surface markers with these molecular subtypes has been previously demonstrated in both cell cultures and patient specimens using FACS and IHC [22, 23].

GSEA predicted DNA replication and cellular growth pathways as enriched in CD133-M subtype tumors and invasion and migration pathways as enriched in CD44-M tumors. This was validated functionally using a panel of GSPCs with CD44+ cells being more invasive and $\mathrm{CD} 44+/ \mathrm{CD} 133+$ cells being more sensitive to temozolomide.

Coexpression module analysis of Pax6 and nestin showed enrichment of the Notch and Hedgehog pathways respectively, supporting the use of these markers for identifying stem/ progenitor cells and validating the targeted coexpression approach for predicting phenotypes associated with markers of interest. However, a limitation of using FACS for functional characterization of marker expressing cells is the requirement for localization of the epitope at the cell surface; both Pax6 and nestin are nuclear proteins and cannot be used for live cell sorting by antibody based methods.

A limitation of our study is the use of mRNA as a surrogate for the expression of cancer stem cell markers. It has recently been demonstrated that there is only a modest correlation between mRNA abundance and protein expression for TCGA tumor specimens [42]. CD133 also undergoes extensive mRNA splicing, generating at least 28 isoforms [43]. The CD133 antibodies used to identify cancer stem cell subpopulations are raised against the glycosylated epitope, which is susceptible to changes in cell cycle phase and oxygen tension [44]. Likewise for CD44, multiple isoforms and glycoslyation states exist $[45,46]$. The CD44v isoform is particularly associated with cancer and metastasis [45]. It is primarily expressed on epithelial cells, during embryonic and hemopoietic development [47]. CD44v is also upregulated in GBM [48]. The microarray measurements used to generate the coexpression signatures do not capture isoform information. Isoform level classification of GBM into molecular subtypes has been demonstrated to improve the power to resolve differences in survival [49].

Although the original description of PN and MES molecular subtypes indicated a survival advantage for 
PN tumors, the discovery of the G-CIMP subgroup of GBM revealed that G-CIMP negative PN tumors had the worst survival of all GBM subgroups $[4,5,50]$. The observation that CD133-M patients receive more benefit from radiotherapy and CD44-M patients receive greater benefit from temozolomide, independent of G-CIMP status is interesting. That CD133 coexpressed genes were involved in cell cycle and DNA replication suggests CD133-M patients would be more susceptible to therapies targeted to highly proliferative cells. The observation that CD133-M patients receive less benefit from temozolomide suggests more complicated mechanisms are involved. Tumors associated with high CD44 expression are known to be more invasive, therefore it is not surprising that it is more difficult to target these tumor cells by radiotherapy. Coexpression analysis indicates that CD15-M is a MES
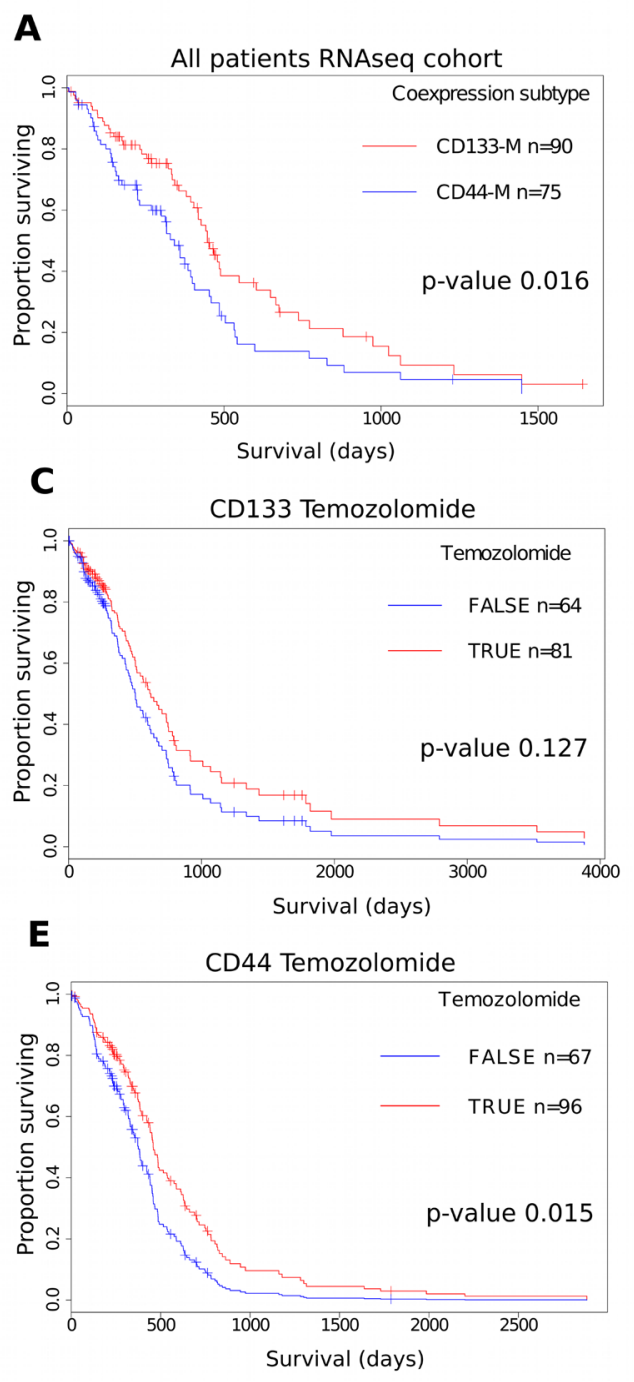

marker. In contrast, functional experiments indicate that CD15 protein expressing cells behave like PN cells [26].

Our study is the first to report triple FACS labeling of GSPCs and did not clarify the relationship of CD15 surface protein expression with CD44 and CD133. Given the small size of our dataset it is difficult to integrate CD15 surface protein expression in the PN-MES spectrum, in the 3 GPSC lines analyzed there was a strong genotypic effect with respect to CD15 expression (Figure 4A)

Therefore the utility of CD15 as a PN or MES marker remains open for further investigation.

It is interesting to note that in our computational analysis of CD133 and CD44 makers there was significant mutual exclusivity in coexpression module signatures. The gene expression measurements in the TCGA represent the average of the tumor population, therefore the mutual
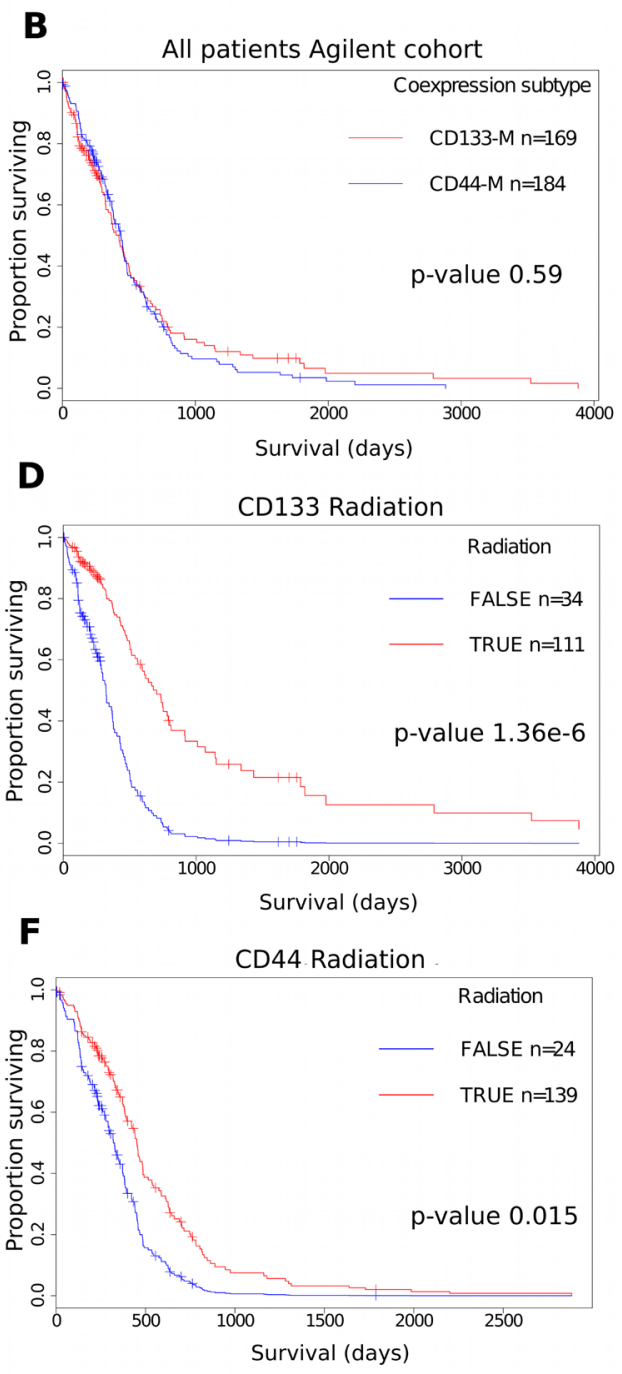

Figure 5: Differential response to therapy for CD44-M and CD133-M classified patients in the TCGA Agilent cohort. (A) Survival advantage for CD133-M classified patients in the TCGA RNAseq cohort. (B) Survival analysis of the TCGAAgilent microarray GBM dataset. CD133-M patients receive greater benefit from radiotherapy. CD133-M classified patients in the Agilent cohort were stratified on the basis of receiving temozolomide (C) or radiotherapy (D). All other covariates are set to the mean of the dataset. CD44-M patients receive greater benefit from temozolomide. CD44-M classified patients were stratified on the basis of receiving temozolomide (E) or radiotherapy $(\mathrm{F})$. 
exclusivity of the CD133-M/ CD44-M signature we have described may be an over simplification. We have not taken into account in our analysis the presence of alternate minor molecular subtypes in a GBM tumor [51, 52].

This may be the reason why there was greater cellular heterogeneity with respect to surface protein expression of CD133, CD44 and CD15 (Figure 4A).

Given that the cancer stem cell theory suggests that stem cells are a rare subpopulation, it is possible that measurements we have used to generate the coexpression signatures do not capture the transcriptome of the GSPCs in vivo.

It has recently been established that in GBM, the PN subtype is the original or ground-state subtype and the other molecular subtypes, including MES are descended from a genetic lineage that arises by clonal evolution. Upon clinical presentation there is generally a dominant subclone which contributes the majority of the gene expression signal [53]. This may be the reason for the mutually exclusive nature of the coexpression subtypes.

The analysis and data generated in this study suggest that CD133 is a marker that enriches for the subpopulation of PN cells that reside in GBMs. PN tumors have been shown to grow more efficiently in vitro and have a greater sphere forming ability [26] and (Figure 4B). In contrast to these more aggressive in vitro characteristics, PN cells form more circumscribed tumors in vivo. MES cells grow more slowly in vitro but are more invasive and vascular in vivo (Figure 4C) and [24]. Therefore the original observations of CD133 expressing cells suggest stemlike properties but may in fact represent the selective advantage these cells have for in vitro conditions. MES cells are more aggressive in vivo, therefore therapies need to target both these infiltrating cells and the progenitor-like PN cells.

The results presented here can assist in the design of phenotypic marker panels for deciphering the cellular heterogeneity inherent in GBM. This study also provides evidence of the utility of molecular subtyping of GBMs along an axis of PN and MES using the expression of CD133 and CD44 protein, thereby providing a technically simple and economical approach for subtyping patient GBM specimens.

\section{METHODS}

\section{Source data}

The analyses performed in this study are in part based upon data generated by the TCGA Research Network [4, 5]. Level 3 RNAseq and Agilent microarray data was obtained from the UCSC cancer genome browser on May 142014 [54]. The Cancer browser in turn obtains processed data from the Broad Institute Firehose pipeline at http://gdac.broadinstitute.org/. Patients that were profiled on both RNAseq and Agilent platforms were removed from the Agilent and retained in the RNAseq dataset. An independent GBM data set was accessed from the Rembrandt database on May 212014 [55]. Molecular subtype per patient was assigned by GSVA using established molecular signatures [4]. The source data from Bhat et al 2013 was downloaded from the Gene Expression Omnibus (GEO) accession number GSE49009, Gunther et al. from GSE8049, Shats et al. from GSE24716 and Rath et al. from GSE63037 [26, 30, $31,33]$. Raw affymetrix CEL files were normalized by the RMA algorithm [56]. Probes values were summarized to a single gene measurement by the average reps function in limma (Linear Models for Microarray Data) [57]. The methylation subgroup was retrieved from the TCGA GBM Oct 2012 data freeze, https://tcga-data.nci.nih.gov/ docs/publications/gbm_2013/TCGA_GBM_dnameth scores_20120112_ver3.txt. G-CIMP, IDH1̄ and MGMT status was obtained from table S7 of Brennan et al. [5]. For all TCGA data the mBatch tool, http://bioinformatics. mdanderson.org/tcgambatch/ was used to inspect for any batch effects. No significant batch effects were observed for the datasets used in this study.

\section{FACS marker coexpression module signature discovery}

The 'corAndPvalue' function from the weighted gene coexpression network analysis package was used to compute the Pearson correlation and p-value under the null hypothesis of the correlation being 0 [58]. Pearson and Spearman correlation derived highly similar results; therefore Pearson correlation was used to compute pairwise gene correlation (Figure S1G and S1H). A cutoff of 2 standard deviations above the mean correlation value and FDR corrected p-value less than 0.05 was used to select the genes for each coexpression module.

\section{Coexpression module signature score computation per patient}

To assign a sample specific score based on enrichment of the derived coexpression modules, the GSVA algorithm was used [41]. GSVA is a non-parametric gene set enrichment method that computes a sample level statistic based on the Kolmogorov-Smirnov random walk statistic. The enrichment score was calculated using the magnitude of the difference between the largest positive and negative random walk deviations. This approach favors genes in pathways that are concordantly activated in one direction only, ie overexpressed relative to the remainder of genes not in the set, as is the case for the standard GSEA algorithm. The coexpression module subtype was designated on a individual patient basis 
by comparing the enrichment scores for CD133-M and $\mathrm{CD} 44-\mathrm{M}$ and assigning a subtype based on the greater value (Figure S1F).

\section{Gene set enrichment of coexpressed genes}

Gene set enrichment analysis was carried out with the java based GUI version 2.2.0.13 [34]. Genes coexpressed with extracellular markers were ranked by the Pearson correlation value and analyzed in preranked mode. Gene set permutation was used to assess statistical significance. The MolSigDB pathway databases interrogated were C2: Canonical Pathways (KEGG, Reactome, Biocarta and PID) for a total of 4722 gene sets.

\section{Cell culture and FACS sorting}

The use of human glioblastoma tissue samples and cell cultures were conducted in accordance with protocols approved by Melbourne Health Human Research and Ethics Committee (HREC number 2009.016). Cells were maintained in DMEM/ F12 (Gibco) supplemented with 10ng/L EGF (bdBiosciences), $10 \mathrm{ng} / \mathrm{L} \quad \mathrm{FGF}$ (bdBiosciences), 1x B27 without vitamin A (Gibco) and 1x Penicillin/ Streptomycin (Gibco). For flow cytometry sorting and analysis, cells were dissociated with accutase (BD Biosciences) and labeled with CD44-FITC (clone DB105, \#130-098-210, Miltenyi-Biotec), CD133APC (clone AC133, \#130-098-829, Miltenyi-Biotec) and CD15-PE (SSEA-1, clone MC-480, \#13-8813-82, eBioscience) along with the relevant isotype controls for gating (Figure S4A). Cells were sorted on a BD FACSAria III and analyzed on a BD LSRFortessa.

\section{Cell biology assays}

For sphere forming assays, 50, 10, 5, 3 and 1 cells per well were plated into flat bottom, ultra low attachment 96 well plates (Corning). A minimum of 6 replicates per cellular dilution was used. Sphere forming efficiency was estimated by limiting dilution analysis using ELDA, [62].

For cell invasion assays, 1000 cells were directly sorted onto round bottom, ultra low attachment 96 well plates (Corning) containing $100 \mu \mathrm{L}$ media. 24 hours later an equal volume of Cultrex BME invasion matrix (Trevigen) was added and incubated for 1 hour at 37 ${ }^{\circ}$ C. An hour later 2 volumes of media was overlaid onto the invasion matrix. 7 days later the spheres were photographed and analyzed by ImageJ version 1.48. Briefly, a manual threshold was applied to mask cells, the image was segmented and the surface area occupied by cells quantified (Figure S4B). Surface area is represented relative to a media only sample to control for proliferation.

Temozolomide sensitivity was measured by sorting
1000 cells directly into flat bottom, ultra low attachment 96 well plates (Corning) containing $100 \mu \mathrm{L}$ media. After 24 hours to allow sphere formation cells were dosed daily with $50 \mu \mathrm{M}$ temozolomide (Sigma-Alrich) with a 50\% media change [63]. Cell number after 7 days of drug exposure was measured by Resazurin assay (R \& D systems). After addition of $10 \% \mathrm{v} / \mathrm{v}$ Resazurin, cells were incubated for 4 hours at $37{ }^{\circ} \mathrm{C}$. Cell number was estimated by fluorescence using an Enspire plate reader at $544 \mathrm{~nm} /$ $590 \mathrm{~nm}$ excitation/ emission.

\section{Statistical analyses}

All analyses were conducted in $\mathrm{R}$ version 3.0.3 unless otherwise stated [59]. The survival package in $\mathrm{R}$ was used to construct a Kaplan Meier plot and build a Cox proportional hazards model [60]. The coin package was used to test for survival differences using a log ranked test [61].

\section{ACKNOWLEDGMENTS}

We thank A/Prof Frederic Hollande and Prof Paul Waring for helpful scientific discussions, Nicole Kountouri and Gulay Filiz for technical help. Josh Kie, Daniel Blashki, Vanta Jameson and Desiree Anthony for flow cytometry assistance. We thank Prof Paul Waring for financial support for DVB PMD, GF and the Cell Signaling Laboratory. We would also like to thank the donors of the tumor-derived GSPC lines and the original samples within the TCGA, Rembrandt and Royal Melbourne Hospital cohorts.

\section{REFERENCES}

1. Miller CR and Perry A. Glioblastoma: morphologic and molecular genetic diversity. Archives of pathology \&amp; laboratory medicine. 2007; 131(3):397-406.

2. Smoll NR, Schaller K and Gautschi OP. Long-term survival of patients with glioblastoma multiforme (GBM). Journal of clinical neuroscience : official journal of the Neurosurgical Society of Australasia. 2013; 20(5):670-675.

3. Phillips HS, Kharbanda S, Chen R, Forrest WF, Soriano RH, Wu TD, Misra A, Nigro JM, Colman H, Soroceanu L, Williams PM, Modrusan Z, Feuerstein BG and Aldape K. Molecular subclasses of high-grade glioma predict prognosis, delineate a pattern of disease progression, and resemble stages in neurogenesis. Cancer Cell. 2006; 9(3):157-173.

4. Verhaak RGW, Hoadley KA, Purdom E, Wang V, Qi Y, Wilkerson MD, Miller CR, Ding L, Golub T, Mesirov JP, Alexe G, Lawrence M, O'Kelly M, Tamayo P, Weir BA, Gabriel S, et al. Integrated genomic analysis identifies clinically relevant subtypes of glioblastoma characterized by abnormalities in PDGFRA, IDH1, EGFR, and NF1. 
Cancer Cell. 2010; 17(1):98-110.

5. Brennan CW, Verhaak RGW, McKenna A, Campos B, Noushmehr H, Salama SR, Zheng S, Chakravarty D, Sanborn JZ, Berman SH, Beroukhim R, Bernard B, Wu C-J, Genovese G, Shmulevich I, Barnholtz-Sloan J, et al. The somatic genomic landscape of glioblastoma. Cell. 2013; 155(2):462-477.

6. Stupp R, Mason WP, van den Bent MJ, Weller M, Fisher B, Taphoorn MJB, Belanger K, Brandes AA, Marosi C, Bogdahn U, Curschmann J, Janzer RC, Ludwin SK, Gorlia T, Allgeier A, Lacombe D, et al. Radiotherapy plus concomitant and adjuvant temozolomide for glioblastoma. The New England journal of medicine. 2005; 352(10):987996.

7. Field KM, Drummond KJ, Yilmaz M, Tacey M, Compston D, Gibbs P and Rosenthal MA. Clinical trial participation and outcome for patients with glioblastoma: multivariate analysis from a comprehensive dataset. Journal of clinical neuroscience : official journal of the Neurosurgical Society of Australasia. 2013; 20(6):783-789.

8. Singh SK, Clarke ID, Terasaki M, Bonn VE, Hawkins C, Squire J and Dirks PB. Identification of a cancer stem cell in human brain tumors. Cancer Research. 2003; 63(18):58215828 .

9. Johnson KW, Dooner M and Quesenberry PJ. Fluorescence activated cell sorting: a window on the stem cell. Current pharmaceutical biotechnology. 2007; 8(3):133-139.

10. Greve B, Kelsch R, Spaniol K, Eich HT and Götte M. Flow cytometry in cancer stem cell analysis and separation. Cytometry Part A : the journal of the International Society for Analytical Cytology. 2012; 81(4):284-293.

11. Marzesco A-M, Janich P, Wilsch-Bräuninger M, Dubreuil V, Langenfeld K, Corbeil D and Huttner WB. Release of extracellular membrane particles carrying the stem cell marker prominin-1 (CD133) from neural progenitors and other epithelial cells. Journal of cell science. 2005; 118(Pt 13):2849-2858.

12. Singh SK, Hawkins C, Clarke ID, Squire JA, Bayani J, Hide T, Henkelman RM, Cusimano MD and Dirks PB. Identification of human brain tumour initiating cells. Nature. 2004; 432(7015):396-401.

13. Metellus P, Nanni-Metellus I, Delfino C, Colin C, Tchogandjian A, Coulibaly B, Fina F, Loundou A, Barrie M, Chinot O, Ouafik LH and Figarella-Branger D. Prognostic impact of CD133 mRNA expression in 48 glioblastoma patients treated with concomitant radiochemotherapy: a prospective patient cohort at a single institution. Annals of surgical oncology. 2011; 18(10):2937-2945.

14. Shibahara I, Sonoda Y, Saito R, Kanamori M, Yamashita Y, Kumabe T, Watanabe M, Suzuki H, Watanabe T, Ishioka $\mathrm{C}$ and Tominaga $\mathrm{T}$. The expression status of CD133 is associated with the pattern and timing of primary glioblastoma recurrence. Neuro-oncology. 2013.

15. Shin JH, Lee YS, Hong Y-K and Kang CS. Correlation between the prognostic value and the expression of the stem cell marker CD133 and isocitrate dehydrogenase 1 in glioblastomas. Journal of neuro-oncology. 2013.

16. Kim K-J, Lee K-H, Kim H-S, Moon K-S, Jung T-Y, Jung S and Lee M-C. The presence of stem cell marker-expressing cells is not prognostically significant in glioblastomas. Neuropathology : official journal of the Japanese Society of Neuropathology. 2011; 31(5):494-502.

17. Fouse SD, Nakamura JL, James CD, Chang S and Costello JF. Response of primary glioblastoma cells to therapy is patient specific and independent of cancer stem cell phenotype. Neuro-oncology. 2013.

18. Stieber D, Golebiewska A, Evers L, Lenkiewicz E, Brons NHC, Nicot N, Oudin A, Bougnaud S, Hertel F, Bjerkvig R, Vallar L, Barrett MT and Niclou SP. Glioblastomas are composed of genetically divergent clones with distinct tumourigenic potential and variable stem cell-associated phenotypes. Acta neuropathologica. 2013.

19. Liu Y, Han SSW, Wu Y, Tuohy TMF, Xue H, Cai J, Back SA, Sherman LS, Fischer I and Rao MS. CD44 expression identifies astrocyte-restricted precursor cells. Developmental biology. 2004; 276(1):31-46.

20. Son MJ, Woolard K, Nam D-H, Lee J and Fine HA. SSEA1 is an enrichment marker for tumor-initiating cells in human glioblastoma. Cell stem cell. 2009; 4(5):440-452.

21. Bao S, Wu Q, Li Z, Sathornsumetee S, Wang H, McLendon RE, Hjelmeland AB and Rich JN. Targeting cancer stem cells through L1CAM suppresses glioma growth. Cancer Research. 2008; 68(15):6043-6048.

22. Lathia JD, Gallagher J, Heddleston JM, Wang J, Eyler CE, MacSwords J, Wu Q, Vasanji A, McLendon RE, Hjelmeland $\mathrm{AB}$ and Rich JN. Integrin alpha 6 regulates glioblastoma stem cells. Cell stem cell. 2010; 6(5):421-432.

23. Lottaz C, Beier D, Meyer K, Kumar P, Hermann A, Schwarz J, Junker M, Oefner PJ, Bogdahn U, Wischhusen J, Spang R, Storch A and Beier CP. Transcriptional profiles of CD133+ and CD133- glioblastoma-derived cancer stem cell lines suggest different cells of origin. Cancer Research. 2010; 70(5):2030-2040.

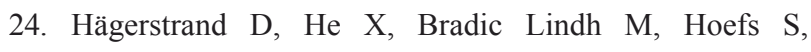
Hesselager G, Ostman A and Nistér M. Identification of a SOX2-dependent subset of tumor- and sphere-forming glioblastoma cells with a distinct tyrosine kinase inhibitor sensitivity profile. Neuro-oncology. 2011; 13(11):11781191.

25. Mao P, Joshi K, Li J, Kim S-H, Li P, Santana-Santos L, Luthra S, Chandran UR, Benos PV, Smith L, Wang M, Hu B, Cheng S-Y, Sobol RW and Nakano I. Mesenchymal glioma stem cells are maintained by activated glycolytic metabolism involving aldehyde dehydrogenase 1A3. PNAS. 2013; 110(21):8644-8649.

26. Bhat KPL, Balasubramaniyan V, Vaillant B, Ezhilarasan R, Hummelink K, Hollingsworth F, Wani K, Heathcock L, James JD, Goodman LD, Conroy S, Long L, Lelic N, Wang 
S, Gumin J, Raj D, et al. Mesenchymal differentiation mediated by NF-?B promotes radiation resistance in glioblastoma. Cancer Cell. 2013; 24(3):331-346.

27. Dong H, Luo L, Hong S, Siu H, Xiao Y, Jin L, Chen R and Xiong M. Integrated analysis of mutations, miRNA and mRNA expression in glioblastoma. BMC systems biology. 2010; 4:163.

28. Sun Y, Zhang W, Chen D, Lv Y, Zheng J, Lilljebjörn H, Ran L, Bao Z, Soneson C, Sjögren HO, Salford LG, Ji J, French PJ, Fioretos T, Jiang T and Fan X. A glioma classification scheme based on coexpression modules of EGFR and PDGFRA. PNAS. 2014; 111(9):3538-3543.

29. Yang Y, Han L, Yuan Y, Li J, Hei N and Liang H. Gene coexpression network analysis reveals common system-level properties of prognostic genes across cancer types. Nature Communications. 2014; 5:3231.

30. Gunther HS, Schmidt NO, Phillips HS, Kemming D, Kharbanda S, Soriano R, Modrusan Z, Meissner H, Westphal $\mathrm{M}$ and Lamszus K. Glioblastoma-derived stem cell-enriched cultures form distinct subgroups according to molecular and phenotypic criteria. Oncogene. 2008; 27(20):2897-2909.

31. Shats I, Gatza ML, Chang JT, Mori S, Wang J, Rich J and Nevins JR. Using a stem cell-based signature to guide therapeutic selection in cancer. Cancer Research. 2011; 71(5):1772-1780.

32. Aruffo A, Stamenkovic I, Melnick M, Underhill CB and Seed B. CD44 is the principal cell surface receptor for hyaluronate. Cell. 1990; 61(7):1303-1313.

33. Rath BH, Fair JM, Jamal M, Camphausen K and Tofilon PJ. Astrocytes enhance the invasion potential of glioblastoma stem-like cells. PLoS ONE. 2013; 8(1):e54752.

34. Subramanian A, Tamayo P, Mootha VK, Mukherjee S, Ebert BL, Gillette MA, Paulovich A, Pomeroy SL, Golub TR, Lander ES and Mesirov JP. Gene set enrichment analysis: a knowledge-based approach for interpreting genome-wide expression profiles. Proceedings of the National Academy of Sciences of the United States of America. 2005; 102(43):15545-15550.

35. Rampazzo E, Persano L, Pistollato F, Moro E, Frasson C, Porazzi P, Della Puppa A, Bresolin S, Battilana G, Indraccolo S, Te Kronnie G, Argenton F, Tiso N and Basso G. Wnt activation promotes neuronal differentiation of Glioblastoma. Cell Death and Disease. 2013; 4(4):e597591.

36. Takezaki T, Hide T, Takanaga H, Nakamura H, Kuratsu $\mathrm{J}-\mathrm{i}$ and Kondo T. Essential role of the Hedgehog signaling pathway in human glioma-initiating cells. Cancer science. 2011; 102(7):1306-1312.

37. Rasper M, Schäfer A, Piontek G, Teufel J, Brockhoff G, Ringel F, Heindl S, Zimmer C and Schlegel J. Aldehyde dehydrogenase 1 positive glioblastoma cells show brain tumor stem cell capacity. Neuro-oncology. 2010; 12(10):1024-1033.
38. Cheng W-Y, Kandel JJ, Yamashiro DJ, Canoll P and Anastassiou D. A multi-cancer mesenchymal transition gene expression signature is associated with prolonged time to recurrence in glioblastoma. PLoS ONE. 2012; 7(4):e34705.

39. Yan X, Maa L, Yia D, Yoonb J-g, Diercksa A, Gregory Foltza b, Pricec ND, Hooda LE and Tian Q. A CD133related gene expression signature identifies an aggressive glioblastoma subtype with excessive mutations. PNAS. 2011:1-13.

40. Holmberg Olausson K, Maire CL, Haidar S, Ling J, Learner E, Nistér M and Ligon KL. Prominin-1 (CD133) Defines Both Stem and Non-Stem Cell Populations in CNS Development and Gliomas. PLoS ONE. 2014; 9(9):e106694.

41. Hänzelmann S, Castelo R and Guinney J. GSVA: gene set variation analysis for microarray and RNA-seq data. BMC bioinformatics. 2013; 14:7.

42. Zhang B, Wang J, Wang X, Zhu J, Liu Q, Shi Z, Chambers MC, Zimmerman LJ, Shaddox KF, Kim S, Davies SR, Wang S, Wang P, Kinsinger CR, Rivers RC, Rodriguez H, et al. Proteogenomic characterization of human colon and rectal cancer. Nature. 2014.

43. Hermansen SK, Christensen KG, Jensen SS and Kristensen BW. Inconsistent immunohistochemical expression patterns of four different CD133 antibody clones in glioblastoma. Journal of Histochemistry and Cytochemistry. 2011; 59(4):391-407.

44. Jaksch M, Múnera J, Bajpai R, Terskikh A and Oshima RG. Cell cycle-dependent variation of a CD133 epitope in human embryonic stem cell, colon cancer, and melanoma cell lines. Cancer Research. 2008; 68(19):7882-7886.

45. Ruiz P, Schwärzler C and Günthert U. CD44 isoforms during differentiation and development. BioEssays : news and reviews in molecular, cellular and developmental biology. 1995; 17(1):17-24.

46. Thorne RF, Legg JW and Isacke CM. The role of the CD44 transmembrane and cytoplasmic domains in co-ordinating adhesive and signalling events. Journal of cell science. 2004; 117(Pt 3):373-380.

47. Günthert U, Hofmann M, Rudy W, Reber S, Zöller M, Haussmann I, Matzku S, Wenzel A, Ponta H and Herrlich P. A new variant of glycoprotein CD44 confers metastatic potential to rat carcinoma cells. Cell. 1991; 65(1):13-24.

48. Jijiwa M, Demir H, Gupta S, Leung C, Joshi K, Orozco N, Huang T, Yildiz VO, Shibahara I, de Jesus JA, Yong WH, Mischel PS, Fernandez S, Kornblum HI and Nakano I. CD44v6 regulates growth of brain tumor stem cells partially through the AKT-mediated pathway. PLoS ONE. 2011; 6(9):e24217.

49. Pal S, Bi Y, Macyszyn L, Showe LC, O'Rourke DM and Davuluri RV. Isoform-level gene signature improves prognostic stratification and accurately classifies glioblastoma subtypes. Nucleic Acids Research. 2014. 
50. Noushmehr H, Weisenberger DJ, Diefes K, Phillips HS, Pujara K, Berman BP, Pan F, Pelloski CE, Sulman EP, Bhat KP, Verhaak RGW, Hoadley KA, Hayes DN, Perou CM, Schmidt HK, Ding L, et al. Identification of a $\mathrm{CpG}$ island methylator phenotype that defines a distinct subgroup of glioma. Cancer Cell. 2010; 17(5):510-522.

51. Sottoriva A, Spiteri I, Piccirillo SGM, Touloumis A, Collins VP, Marioni JC, Curtis C, Watts C and Tavaré S. Intratumor heterogeneity in human glioblastoma reflects cancer evolutionary dynamics. PNAS. 2013.

52. Patel AP, Tirosh I, Trombetta JJ, Shalek AK, Gillespie SM, Wakimoto H, Cahill DP, Nahed BV, Curry WT, Martuza RL, Louis DN, Rozenblatt-Rosen $\mathrm{O}$, Suvà ML, Regev $A$ and Bernstein BE. Single-cell RNA-seq highlights intratumoral heterogeneity in primary glioblastoma. Science. 2014; 344(6190):1396-1401.

53. Ozawa T, Riester M, Cheng Y-K, Huse JT, Squatrito M, Helmy K, Charles N, Michor F and Holland EC. Most Human Non-GCIMP Glioblastoma Subtypes Evolve from a Common Proneural-like Precursor Glioma. Cancer Cell. 2014; 26(2):288-300.

54. Cline MS, Craft B, Swatloski T, Goldman M, Ma S, Haussler D and Zhu J. Exploring TCGA Pan-Cancer data at the UCSC Cancer Genomics Browser. Scientific reports. 2013; 3:2652.

55. Madhavan S, Zenklusen JC, Kotliarov Y, Sahni H, Fine HA and Buetow K. Rembrandt: helping personalized medicine become a reality through integrative translational research. Molecular cancer research : MCR. 2009; 7(2):157-167.

56. Irizarry RA, Hobbs B, Collin F, Beazer-Barclay YD, Antonellis KJ, Scherf U and Speed TP. Exploration, normalization, and summaries of high density oligonucleotide array probe level data. Biostatistics (Oxford, England). 2003; 4(2):249-264.

57. Smyth GK. Linear models and empirical bayes methods for assessing differential expression in microarray experiments. Statistical Applications in Genetics and Molecular Biology. 2004; 3:Article3.

58. Langfelder $\mathrm{P}$ and Horvath S. WGCNA: an R package for weighted correlation network analysis. BMC bioinformatics. 2008; 9:559.

59. R Core Team. R: A language and environment for statistical computing. R Foundation for Statistical Computing, Vienna, Austria. 2014; URL http://www.R-project.org/.

60. Therneau TM and Grambsch PM. Modeling Survival Data: Extending the Cox Model. Springer, New York. 2000; ISBN 0-387-98784-3.

61. Hothorn T, Hornik K, van de Wiel MA, Zeileis A. Implementing a Class of Permutation Tests: The coin Package. Journal of Statistical Software. 2008; 28(8):1-23.

62. $\mathrm{Hu}$ Y and Smyth GK. ELDA: extreme limiting dilution analysis for comparing depleted and enriched populations in stem cell and other assays. Journal of immunological methods. 2009; 347(1-2):70-78.
63. Beier D, Schriefer B, Brawanski K, Hau P, Weis J, Schulz JB and Beier CP. Efficacy of clinically relevant temozolomide dosing schemes in glioblastoma cancer stem cell lines. Journal of neuro-oncology. 2012. 